\title{
Effects of Creative Convergence Class of Design Thinking on Improving University Students' Creativity Confluence Competency and Problem-Solving Ability
}

\author{
Chungyun $\mathrm{Kim}^{1}$ \\ ${ }^{1}$ Sangji University, Gangwondo, Korea \\ ${ }^{1}$ smcutefany@naver.com
}

\begin{abstract}
This study analyzed the effects of design-thinking-based creativity competency class on the improvement of college students' creativity convergence competency and problem-solving ability. For 15 weeks in one semester, 52 college students in the experimental group took a creativity convergence class based on design thinking, and 50 college students in the control group took a creative thinking development class. To measure the creativity convergence competency and problem-solving ability of university students, pre-test and post-test were conducted using the university student's creativity convergence competency test and the university student's problem-solving ability test. As a result of this study, it was found that the creativity convergence class based on design thinking is effective in improving the creativity convergence competency and problem-solving ability of university students. The results of this study imply that it is necessary to improve and implement a differentiated creativity convergence curriculum in each university because the creativity convergence class using design thinking can improve the creativity convergence competency and problem-solving ability of university students.
\end{abstract}

Keywords: Design thinking, Creativity convergence, Creativity convergence competency, Problem-solving ability, University students

\section{Introduction}

Creativity is no longer the exclusive property of a handful of geniuses and is regarded as an essential competency that all can be developed through learning and training. This creativity is the ability and character to create new and original products, which shows that creativity is related to problem-solving. However, to develop such creativity, the need for a creativity convergence education that can solve various and complex problems has been raised as the area-integrative view that areas generality and area specificity must be considered is emphasized [1]. Accordingly, in a situation where interest in teaching innovation methods that can go beyond the limits of unilateral lecture-style education is increasing, design thinking can improve creativity convergence competency and problem-solving ability that can solve fusion and complex problems. This is attracting attention.

Design Thinking is a creative problem-solving process in which people can get creative ideas that can solve problems through intuition and analysis. This is effective in promoting group creativity while solving problems by utilizing human-centered emotional empathy and

Article history:

Received (July 8, 2020), Review Result (August 21, 2020), Accepted (October 2, 2020) 
ideas based on knowledge and information in various fields. Such design thinking is already used in various fields such as education, medical care, administration, etc. at home and abroad, and it is possible to effectively grasp the true needs and potential needs of users and customers so that ideas that can solve problems through the step of empathy before the idea is derived. Make it possible to derive. Therefore, design thinking can be said to be a desirable learning strategy for creating creative and fusion ideas using learners' knowledge in various fields and solving problems effectively. Also, as a way to solve and overcome multifaceted problems while preparing for the 4th industrial society, university students can learn usercentered, field-oriented creative strategies across majors and fields.

Design Thinking is proposed as a process of defining problems based on empathy for problems and innovatively solving problems through collaboration with colleagues. In particular, this was originally used as a process to improve products or solutions based on human-centered thinking in the mechanical engineering sector, but recently it has been applied in various fields and social innovation fields. In recent years, lectures using design thinking are being conducted in various majors, and attempts are being made to enhance creative fusion capabilities through a fusion of major knowledge. To this end, each university is actively seeking practical strategies to cultivate creative and convergent talents, and university students creatively solve problems by integrating various knowledge and information through convergent thinking, creating ultimate future values, and creating a new paradigm. We are striving to develop creative and convergent talents who can lead the world. To achieve this, a creative fusion class is being conducted, and the class has creative leadership that respects and empathizes with the creative ability and personality, and the opinions of others, and enables the creation of high-quality creative products through flexible communication and dissent. It is possible to develop creativity convergence competency that can create fusion values that can lead a new paradigm through ethical thinking [2].

Creativity Convergence Class is an education designed to foster creativity by allowing college students to analyze everyday problems from various angles and find alternatives to problems related to their career after graduation through original and flexible thinking. In particular, by the time the current university students graduate, more and more new career groups emerge, enabling practical application of theories, dealing with problems in the convergent and complex areas, and providing concrete methods to innovatively solve problems through collaboration with colleagues. The value of perspective will be valued. Therefore, students who are studying various majors can discuss and collaborate in a creative fusion class that can solve problems through collaboration, and develops creative fusion capabilities by combining humanities imagination and science and technology creativity [3].

Meanwhile, with the development of IT technology and new business, the boundaries between different areas become unclear and problems that are difficult to solve with individual academic knowledge arise. To solve these problems, not only creativity but also convergence through interdisciplinary interaction or cooperation is required. However, in order not to cultivate talented people specialized in only one field, but to cultivate talented people who have a variety of convergent thinking and personality, classes that emphasize team-centered project activities are being conducted. This is a class that enables learners to solve problems through active participation and creative design. Recently, design thinking has been applied in the class, and activities to actively transform or recreate learning content are encouraged [4]. Therefore, it is necessary to study how the creative fusion class based on design thinking affects the creative fusion capacity and problem-solving ability of university students, and the effectiveness of the creative fusion class operation model and strategy 
through the results of this study needs to be verified. And there is a need for continuous improvement based on this.

Accordingly, in this study, an experimental study was conducted to confirm the effect of design-thinking-based creative fusion class for college students on the improvement of college students' creative fusion capability and problem-solving ability. And the following research questions were set according to the necessity and purpose of this study.

Research Question 1. Is Creativity Convergence Class based on Design Thinking Effective in Improving University Students' Creativity Convergence Competency?

Research Question 2. Is Creativity Convergence Class Based on Design Thinking Effective in Improving University Students' Problem-Solving Ability?

\section{Background}

Creativity is a capability that can be developed through learning and training, so creativity can be improved through design thinking, and we have focused on the possibility of design thinking to promote creativity in the recent education field. It is a trend that is applied and spread. Design Thinking is the process of creatively solving problems through five steps of repetition of prototype production and testing by defining problems through user sympathy by borrowing the designers' mindset that repeats diffusion and convergence. to be. Stanford dschool, where education is conducted by applying design thinking with the world's leading design consulting company IDEO most actively, is a technically viable design thinking method that responds to the needs of people, it was also defined as a kind of methodology that utilizes the designer's emotions and methods for the execution of business strategies that can be turned into opportunities. Also, to solve complex problems, it is said that users' positive reactions, affinity, and feasible technical possibilities are identified, and experts in various fields collaborate to solve problems creatively and innovatively. In particular, schools operate a convergence education program to allow students to experience the design process by incorporating design thinking into other disciplines and conducts practical and experienceoriented education by using not only theory but also intuitive thinking and analytical thinking in a balance [5].

Many scholars have emphasized an integrative approach to creativity, as creativity is determined through individual cognitive abilities, affective tendencies, and interactions with environments and tasks. Accordingly, since higher education is also interested in the application of this integrated approach and creative fusion education that goes beyond the boundaries of disciplines, creativity and fusion are not viewed as separate recruits, but a total dimension that includes not only abilities and attitudes but also practical actions. There is a need for an approach to creative fusion capabilities. Accordingly, [6] verified the creative fusion capability as a single concept that is not separated into creative capability and fusion capability. Also, creative fusion talents are creative, cross the boundaries of two or more disciplines, think fusion, create new and original values, and exercise creative leadership, and share their values in their academic, social, economic, cultural, and social It was defined as a future-oriented human resource that deviated from the traditional paradigm of thinking through creative fusion capabilities that can be spread throughout the development of the country.

Creativity Convergence Capability is a new convergence through convergent thinking that can apply and apply knowledge and skills in various academic fields by understanding, analyzing, and reasoning, with creative ability to solve problems creatively, creative personality, and creative leadership. It is the ability to create unique value [7]. Specifically, 
the definition of the sub-factor is as follows. Creative ability is the ability to generate new and diverse ideas and to come up with creative alternatives. The creative personality is an individual's affective trait that enables the creative ability to achieve final achievements while producing output. Creative leadership is a leadership that adapts to society through active self-management, respects others, and encourages the creation of creative convergence products using various resources through community cooperation. Convergence thinking is a thinking ability that can understand, analyze, infer, and apply and apply knowledge and skills in various fields. And fusion value creation is the ability to create new knowledge and value through a cross-disciplinary approach.

Convergence is necessary to create new knowledge and information based on knowledge of various disciplines and to creatively solve new phenomena or problems. In particular, creative leadership with insight and creative ideas is important when conducting collaborative activities and projects with colleagues majoring in various majors through creative convergence education and presenting ideas among members. And creative leadership can be developed, and through this, convergent thinking can be promoted more effectively. In other words, through the role of a creative leader who encourages creativity among members, it is possible to derive creative ideas while thinking about the links between knowledge in various fields. Also, it is possible to create a convergent value that can create knowledge utility value by creating new knowledge through convergent thinking beyond simply knowing knowledge and applying it. To create new products while solving problems creatively, it is required to improve the creative fusion capacity of university students [8]. However, the level of research and development of classes aimed at fusion between different majors by analyzing the creative fusion capabilities of university students is insufficient.

On the other hand, the problem-solving ability is a creative and intellectual ability to grasp the difference between the current state and the target state and resolve it. To solve the problem in this way, there must be a goal to be solved, and a process and procedure must be carried out to achieve the goal [9]. There are two perspectives on such problem-solving ability as follows. First, the problem is solved based on rational and rational thinking by subdividing various problems by component, defining problems, and analyzing the relationship between sub-factors. Second, it solves problems based on creativity and intuition. Through this, it can be seen that creativity is related to problem-solving, and considering that creativity is the basis for enabling convergence, it can be seen that creative fusion capacity can be enhanced through problem-solving. Therefore, creative fusion classes based on design thinking that can promote creative fusion capabilities and problem-solving skills, which are the foundation for enabling creativity and fusion, which is the core of the future society, should be actively conducted. For this purpose, the results of this study can be the basic data for more effective implementation of creative convergence education in universities [10][11].

\section{Research method}

At University A, for 15 weeks in one semester, 52 students in the experimental group took a lecture on "Design Thinking and Creativity Convergence", and 50 students in the control group took a lecture on "Development of Creative Thinking".

For 15 weeks, the researcher directly distributed a questionnaire to the experimental group and the control group college students and conducted a creative fusion competency test and a problem-solving ability test. The response data that responded faithfully to the two tests were statistically processed using SPSS 25.0, and independent sample t-tests were conducted for research questions 1 and 2 . 
In this study, the creative convergence competency measurement tool developed and validated by Kim was used to determine the level of creative convergence competency of college students in teacher education. Since this tool has been verified for cross-validity by gender, grade, major, and region, when this tool is used, measurement results can be consistently calculated for each background variable. The $5 \mathrm{C}$ model is based on the $5 \mathrm{sub}-$ factors, and the sub-factors are creative ability, creative personality, creative leadership, convergent thinking, and convergent value creation (convergent value creation), a total of 59 questions. The overall test is a 5-point Likert scale with 1 point of 'not at all' to 5 points of 'very much', and the reliability is Cronbach's $\alpha .963$, which is a reliable tool.

The problem-solving ability test used to diagnose the problem-solving ability of college students was a tool for measuring problem-solving ability for college students among the lifelong ability measurement tools developed by Seok-Jae Lee and others. Five factors: problem clarification (problem recognition), cause analysis (information collection, analysis), alternative development (diffuse thinking, decision-making), planning and execution (planning ability, execution, and risk-taking), performance evaluation (evaluation, feedback) It consists of 9 sub-factors presented in parentheses and a total of 45 questions. The whole test is composed of a Likert 5-point scale with 1 point of 'not at all' to 5 points of 'very much', and the reliability is Cronbach's $\alpha .868$, which is a relatively reliable tool.

\section{Research results}

From the results of the preliminary test for creative fusion competency and problemsolving abilities conducted before the experiment, it was confirmed that there is a homogeneity in the creative fusion abilities and problem-solving abilities of the experimental and control groups ( $p>.05)$. Accordingly, a t-test was conducted and compared with the score of the post-test between the two groups. The results were as follows.

There was a statistically significant difference between the two groups in the creative ability, creative personality, creative leadership, fusion thinking, and fusion value creation factors of creative fusion competency $(\mathrm{p}<.05)$. Also, there were statistically significant differences between the two groups in problem clarification, cause analysis, planning and execution, performance evaluation, and each sub-factor in problem-solving ability $(\mathrm{p}<.05)$, but in diffuse thinking of alternative development, between the two groups There was no statistically significant difference ( $p>.05)$.

\section{Discussion}

In this study, the effect of design-thinking-based creative fusion class on the improvement of creative fusion capability and problem-solving ability of university students was confirmed. And the contents of the discussion and conclusion of the results of this study are as follows.

Creativity is no longer the exclusive property of a handful of geniuses and is regarded as an essential competency that everyone can develop through learning and training. This creativity is the ability and character to create new and original products, which shows that creativity is related to problem-solving.

However, to develop such creativity, the need for a creative convergence education that can solve a variety of complex problems has been raised as the area-integrated view that domain generality and domain specificity must be considered is emphasized.

Creative behavior is the result of the interaction between the individual and the environment (situation). Personal factors include cognitive aspects (cognitive type and 
ability) and non-cognitive aspects (personality characteristics, motivations, and values, etc.), and environmental factors include a wide range of contextual influences (physical environment, cultural factors) and microscopic social influences (competition). And students can become more creative in a free, supportive, and comfortable atmosphere. Therefore, this study proved that the creative fusion class based on design thinking in consideration of cognition, definition, and environmental aspects contributes to the improvement of the competencies of university students.

Duckworth and colleagues point out that not only cognitive competencies but also noncognitive competencies have a great influence on an individual's attitudes and behaviors. It was defined as. Grit is a long-term passion and persistence for success, which consists of two sub-factors: consistency of interest and persistence of effort. In other words, it is the grit that continuously strives for a long time while maintaining interest and interest in the goal to be achieved. The factors that determine success are not cognitive competencies such as intelligence or academic achievement, but persistence, patience, sincerity, human relations, confidence, and self-regulation. And creative leadership, understanding, analyzing, and reasoning knowledge and skills in various academic fields, applying them and creating new convergent values through convergent thinking that can be applied.

Creativity Convergence Class can promote creative fusion competencies by providing education to promote creative fusion competencies such as creative ability, creative personality, creative leadership, fusion thinking, and fusion value creation. This is closely connected with the definition of a person who can create new value by combining various knowledge and creating new knowledge with humanities imagination, science and technology creativity, and good personality in the Ministry of Education. Therefore, if you make consistent interest and consistent efforts to succeed with long-term passion and persistence after graduation, you can develop not only creative fusion capabilities but also grit.

The Creative Convergence Class that applied design thinking, which can be practically helpful to college students, improved the creative fusion skills and problem-solving skills of college students. Therefore, in a class where you need to solve problems by creating convergent and complex ideas such as Capstone Design by applying these classes from the liberal arts class and linking the liberal arts class with the major class, you can further demonstrate your creative fusion capability and problem-solving skills. There will be opportunities to be provided.

\section{References}

[1] A. J. Croply, "Creativity in education and learning: A guide for teacher and educations," London: Kogan Page, (2001)

[2] C. Y. Kim, "Development and validation of college students' creative convergence capability measurement tools," Ph. D. Dissertation, Soongsil University General Graduate School, (2017)

[3] R. Frodeman, J. T. Klein, and C. Mitcham, "The oxford handbook of interdisciplinarity," UK: Oxford University Press, (2010)

[4] R. W. Greene and J. S. Ablon, "Treating explosive kids: The collaborative problem-solving approach,” New York: The Guilford Press, (2006)

[5] G. T. Brown, "Change by design: How design thinking transforms organizations and inspires innovation," New York: HarperCollins, (2009)

[6] C. Y. Kim, "University students' perception and demand for creative convergence education," Integrated Curriculum Research, vol.12, no.3, pp.149-174, (2018) 
[7] C. Y. Kim and K. H. Lee, "University students' creativity convergence competency 5C model verification," Arts, Humanities and Social Convergence Multimedia Journal, vol.7, no.7, pp.89-97, (2017)

[8] T. Kelley and D. Kelley, "Creative confidence: Unleashing the creative potential within us all," Crown Business, (2013)

[9] S. J. Lee, Y. K. Jang, H. N. Lee, and K. Y. Park, "Research on the development of life-long ability measurement tools: Focusing on communication skills, problem-solving skills, and self-directed learning skills," Seoul: Korea Educational Development Institute, (2003)

[10] A. L. Duckworth, C. Peterson, M. D. Matthews, and D. R. Kelly, "Grit: Perseverance and passion for longterm goals" Journal of Personality and Social Psychology, vol.92, no.6, pp.1087-1101. (2007)

[11] Ministry of Education "2015 revision direction of the curriculum. Ministry of education" (2015) 
Effects of Creative Convergence Class of Design Thinking on improving University Students' Creativity Confluence Competency and Problem-Solving Ability

\section{This page is empty by intention}

